Introduction: The way to improve the efficiency of chemotherapy of malignant gliomas may be combined administration of alkylating agents and those targeted at epithelial growth factor receptor (EGFR). The patients eligible for such therapy should show hypermethylation of MGMT (O6-methylguanineDNA-methyltransferase) promoter as well as amplification of EGFR.

Aim of the study: Preliminary assessment of frequency of MGMT hypermethylation and amplification of EGFR co-occurrence in malignant gliomas in patients diagnosed and operated on in the Neurosurgery Department, JUMC in Cracow. Material and methods: 21 consecutive cases of glioblastoma multiforme (W 65\%, M 35\%, age average $51 \mathrm{y}$ ). The methylation status of the MGMT promoter was determined by methylationspecific PCR (MS-PCR). Before MS-PCR, genomic DNA was treated with sodium bisulphite, purified, denatured, precipitated and eluted. EGFR amplification was investigated using the FISH method. Results: With regards to MGMT methylation status and the occurrence of EGFR amplification, four groups of tumours (patients) were established: I - hypermethylation and amplification (4/21, 19.04\%); II - hypermethylation, no amplification (6/21, 28.6\%); III - no hypermethylation with amplification (4/21, 19.04\%); IV - no hypermethylation, no amplification (7/21, 33.3\%).

Conclusions: Theoretically almost one fifth (19\%) of patients with glioblastoma multiforme, i.e. those featuring MGMT hypermethylation and EGFR amplification, could potentially benefit from bimodal chemotherapy with an alkylating agent and an EGFR blocker. Our results confirm other reports indicating that there are no relations between MGMT methylation and EGFR amplification.

Financial support by Grant No. K/ZDS/ 001044 Jagiellonian Univ.

Key words: MGMT promoter methylation, EGFR amplification, glioblastoma, FISH, MS-PCR, bivalent therapy.

\section{Co-occurrence of MGMT gene promoter methylation and amplification of EGFR in glioblastoma}

\author{
Dariusz Adamek ${ }^{1}$, Monika Zazula ${ }^{\text {la }}$, Edyta Radwańska ${ }^{1}$ Ewelina Grzywna², \\ Anna Sińczak-Kuta ${ }^{1}$, Marek Moskała ${ }^{2}$
}

\begin{abstract}
${ }^{1}$ Chair and Department of Pathomorphology, Jagiellonian University Medical College, Krakow, Poland

1anow: Oncogene Diagnostics Sp. z o.o., Krakow, Poland

2Department of Neurosurgery and Neurotraumatology, Jagiellonian University Medical College, Krakow, Poland
\end{abstract}

\section{Introduction}

Gliomas are the most common primary brain tumours. According to the most important features, i.e. vascular proliferation, degree of cellularity/atypia, and necroses, they are classified into four WHO grades. Glioblastoma multiforme (GBM) is the grade 4 glioma derived from astrocytes. It constitutes about $55 \%$ of all gliomas, and is more common in male Caucasians. The prognosis in GBM is extremely poor with median survival rate about 10-15 months and 75\% mortality rate in the first 1.5 year from diagnosis. Histopathologically there are two subgroups of glioblastoma, primary ('de novo') and secondary (from the lower grade glioma) glioblastoma. Despite years of investigations, the treatment of glioblastoma is still unsatisfactory [1]. New agents are being investigated.

Significant development of diagnostic methods based on molecular techniques and neuroimaging has changed the knowledge concerning diagnosis and treatment of central nervous system neoplasms. Glia-derived primary brain tumours have become a dynamic area of molecular studies. Information from molecular diagnostics may have crucial importance in the diagnostic and treatment process.

The way to improve the efficiency of chemotherapy of malignant gliomas may be the combined administration of alkylating agents and those targeted at epithelial growth factor receptor (EGFR). The patients eligible for such therapy should show hypermethylation of MGMT (06-methylguanine-DNAmethyltransferase) promoter as well as amplification of EGFR.

\section{Material and methods}

21 consecutive cases of glioblastoma multiforme were studied: patients (W 65\%, M 35\%, age average 51 y) operated on in the Neurosurgery Department of Jagiellonian University Medical College (JUMC) and neuropathologically diagnosed in the Department of Neuropathology, Chair of Pathomorphology, JUMC in Cracow. The methylation status of the MGMT promoter was determined by methylation-specific PCR (MS-PCR). Before MS-PCR, genomic DNA was treated with sodium bisulphite, purified, denatured, precipitated and eluted. EGFR amplification was investigated using the FISH method.

O6-methylguanine methyltransferase (MGMT) promoter methylation analysis with methylation-specific PCR (MS PCR)

Tissue samples, not immersed, frozen to the temperature of $-80^{\circ} \mathrm{C}$ directly after tumour resection were used for analysis.

DNA isolation sterile removed tissue was fragmented, placed in a $1.5 \mathrm{~mL}$ Eppendorf tube, fast-frozen in liquid nitrogen and kept at a temperature of $-80^{\circ} \mathrm{C}$. The genomic DNA isolation from the tumour and from the control tissue was performed using the QIAamp DNA Mini Kit (Qiagen GmbH, Germany) according to the manufacturer's protocol. 
MGMT promoter methylation detection:

Using the methylation-specific PCR (MSP) method, the level of methylation in the CpG-rich DNA region of the MGMT gene promoter was evaluated. The applied method is based on the chemical modification (deamination) of the DNA sample with sodium disulphide. In this reaction unmethylated cytosine is changed to uracil, and in PCR finally to thymine. PCR involved the use of primers (Polgen, Metabion) specific for methylated promoter fragment: MET-MGMT-F 5'-GCACTCTTCCGAAAACGAAAC-3' and MET-MGMT -R 5'-TTTC GACGTTCGTAGGTTTTC-3', and for detection of umethylated promoter fragment: UM-MGMT-F 5'-TTTGTGTTTTGAT GTTTGTAGGTTTTTGT-3' and UM-MGMT -R '-AACTCCACACT CTTCCAAAAA-3'.

In this way false positive results were eliminated. The PCR reactions (32 cycles) were performed including an initial denaturation of $10 \mathrm{~min}$ at $95^{\circ} \mathrm{C}$ and subsequent denaturation for $45 \mathrm{~s}$ at $95^{\circ} \mathrm{C}$, annealing for $45 \mathrm{~s}$ at $62^{\circ} \mathrm{C}$ and extension for $1.5 \mathrm{~min}$ at $72^{\circ} \mathrm{C}$. PCR reactions were performed in $30 \mu$ of $25 \mathrm{mM} \mathrm{MgCl}$, with $1.2 \mu \mathrm{l}$ dNTP (Applied Biosystems Inc.), $20 \mu \mathrm{M}$ of each primer and $0.5 \mathrm{U} / \mu \mathrm{l}$ Gold Taq DNA Polymerase (Applied Biosystems Inc.) Amplification products were separated on $2 \%$ agarose gel (110 V, approx. $25 \mathrm{~min}$ ) and visualized by ethidium bromide staining.

\section{Epidermal growth factor receptor (EGFR) amplification analysis with the FISH method}

FISH was done on 4-5- $\mu$ m-thick formalin-fixed paraffinembedded tissue sections (FFPE) using Paraffin Pretreatment Kit (No.32-80120) and LSI/EGFR/CEP 7 FISH Probe kit (No. 32-191053, Vysis, Inc., Downers Grove, IL, USA). The kit uses a dual-color probe for determining the number of copies of EGFR gene (labelled with SpectrumOrange dye) and the centromeric region of chromosome 7 (7p11.1-q11.1 Alpha Satelite DNA) is labelled with SpectrumGreen dye. In brief, tissue sections were deparaffinized and dehydrated in $100 \%$ ethanol and air dried. Slides were then pretreated with $0.2 \mathrm{M}$ hydrochloric acid for 20 minutes (RT), immersed in Pretreatment Solution at $80^{\circ} \mathrm{C}$ for 30 minutes and digested in protease solution for 27 minutes at $37^{\circ} \mathrm{C}$. Then $8 \mu$ l of probe was applied on tissue sections and the slides were denatured $\left(72^{\circ} \mathrm{C}\right.$ for 5 minutes), hybridized at $37^{\circ} \mathrm{C}$ overnight in hybridizer MP-16 (Hiperon, Genos). After hybridization, the slides were washed with Post-Hybridization Wash Buffer (2xSSC, 0.3\% NP-40, pH 7.0-7.5) at $72^{\circ} \mathrm{C}$ for 3 minutes. The slides were air-dried and 4'-6'-diamidino-2'-phenylindole (DAPI) counterstain was applied. Samples were evaluated with the Nikon fluorescence microscope. For the normal numbers of copies of the EGFR gene and chromosome 7, two orange and two green signals should be observed, respectively. Three or more orange signals with two green signals for chromosome 7 indicates extra copies of the EGFR gene (EGFR amplification). More than two green signal in the nucleus means polyploidy.

\section{Results}

The results are summarized in Table 1.

10/21 (47.6\%) cases showed MGMT promoter hypermethylation and 8/21 (38.1\%) showed amplification of EGFR.
According to the MGMT promoter methylation and EGFR amplification status the investigated patients form four groups: - MGMT promoter methylation and EGFR amplification present: 4/21 (19.04\%) (an example illustrated in Fig. 1),

- MGMT promoter methylation present, no EGFR amplification: 6/21 (28.6\%) (an example illustrated in Fig. 2),

- no MGMT promoter methylation, EGFR amplification present: 4/21 (19.04\%) (an example illustrated in Fig. 3),

- no MGMT promoter methylation, no EGFR amplification: 7/21 (33.3\%) (an example illustrated in Fig. 4).

\section{Discussion}

Tumour histopathology and neoplastic cells' sensitivity to different strategies of treatment seem to be associated with specific molecular features. It should be reasonable to adjust the treatment approach to the particular molecular tumour phenotype and this is the idea of personalized therapy in oncology. At least three molecular markers of clinical significance in gliomas are already indentified: 06-methylguanine methyltransferase (MGMT) promoter methylation, 1p/19q codeletion, and isocitrate dehydrogenase-1 mutations (IDH1). All of them are favourable prognostic factors, and some also have predictive value. Also the classic molecular markers of cancerogenesis, such as p53 status and epidermal growth factor receptor (EGFR) amplification, are discussed in gliomas [2].

\section{MGMT promoter methylation}

O6-methylguanine methyltransferase is a DNA repair protein. Its function is to remove the alkyl group from the $\mathrm{O}^{6}$-guanine position to prevent DNA failure and cell death. MGMT promoter hypermethylation stops the MGMT transcription. Theoretically, it makes the neoplastic cells' DNA more sensitive to damage from alkylating agents. In conclusion, MGMT promoter methylation has potential predictive value for this type of chemotherapy (e.g. with temozolomide).

Clinical trials have already been undertaken to investigate the correctness of this approach. Thus, in the EORTC trial $22033-26033$ primary chemotherapy with temozolomide v. radiotherapy alone in grade $I$ WHO astrocytic brain tumours has been compared. MGMT status in those patients (stratified for $1 p$ loss already) has been assessed to determine whether MGMT promoter methylation affects the benefit from temozolomide therapy. In the CATNON trial (anaplastic gliomas) four patient groups according to $1 p / 19 q$ loss and MGMT promoter methylation have been designed and the efficiency of temozolomide in the concurrent, adjuvant or both settings with radiotherapy was investigated [3]. The CODEL project, focused on the newly diagnosed anaplastic oligodendrogliomas and anaplastic mixed gliomas with $1 p / 19 q$ codeletion, compared three strategies of treatment: radiotherapy alone, temozolomide chemotherapy alone, and radiochemotherapy with temozolomide [4].

The most powerful results, according to newly diagnosed glioblastoma patients' management, have been obtained in the EORTC NCIC trial. The EORTC NCIC investigators reported an increase of the median survival (from 12.1 to 14.6 months) and of the two-year survival rate (from 10 to 26\%) for patients treated with combined radio- and chemotherapy with temozolomide. They were able to present a signifi- 
Table 1. Summary of the investigations of MGMT promoter methylation status and amplification of EGFR in glioblastoma

\begin{tabular}{|c|c|c|c|c|c|c|}
\hline No. & $\begin{array}{l}\text { MGMT } \\
\text { methylation } \\
\text { status* }\end{array}$ & $\begin{array}{l}\text { Green } \\
\text { signalling } \\
\text { (CEN7) - } 60 \text { cell } \\
\text { nuclei average }\end{array}$ & $\begin{array}{l}\text { Orange } \\
\text { signalling } \\
\text { (EGFR) } \\
\text { - } 60 \text { cell nuclei } \\
\text { average }\end{array}$ & $\begin{array}{l}\text { EGFR/CEN7 } \\
\text { ratio } \\
\text { - no amplification } \\
\text { - overamplification } \\
\text { - ploidy }\end{array}$ & EGFR copies & $\begin{array}{l}\text { Ploidy; } \\
-60 \text { cell } \\
\text { nuclei } \\
\text { average }\end{array}$ \\
\hline 1. & UNMET & $\begin{array}{l}4.2 \\
(2-8 / \text { nucleus })\end{array}$ & $\begin{array}{l}4.4 \\
(2-8 / \text { nucleus })\end{array}$ & 1.05 & $\begin{array}{l}\text { - no amplification } \\
\text { - tetraploidy }\end{array}$ & $4 n$ \\
\hline 2. & UNMET & $\begin{array}{l}3.6 \\
(2-4 / \text { nucleus })\end{array}$ & $\begin{array}{l}29.9 \\
(8-38 / \text { nucleus })\end{array}$ & 6.37 & $\begin{array}{l}\text { - overamplification } \\
\text { - tetraploidy }\end{array}$ & $4 n$ \\
\hline 3. & MET & $\begin{array}{l}2.8 \\
(2-4 / \text { nucleus })\end{array}$ & $\begin{array}{l}2.9 \\
(2-4 / \text { nucleus })\end{array}$ & 1.03 & $\begin{array}{l}\text { - no amplification } \\
\text { - triploidy }\end{array}$ & $3 n$ \\
\hline 4. & UNMET & $\begin{array}{l}3.1 \\
(2-4 / \text { nucleus })\end{array}$ & $\begin{array}{l}20.1 \\
\text { (15-30/nucleus) }\end{array}$ & 6.48 & $\begin{array}{l}\text { - overamplification } \\
\text { - triploidy }\end{array}$ & $3 n$ \\
\hline 5. & UNMET & $\begin{array}{l}4.9 \\
(2-6 / \text { nucleus })\end{array}$ & $\begin{array}{l}31.9 \\
\text { (16-60/nucleus) }\end{array}$ & 6.51 & $\begin{array}{l}\text { - overamplification } \\
\text { - pentaploidy }\end{array}$ & $5 n$ \\
\hline 6. & MET & $\begin{array}{l}3.2 \\
(2-6 / \text { nucleus })\end{array}$ & $\begin{array}{l}29.3 \\
(16-46 / \text { nucleus })\end{array}$ & 9.1 & $\begin{array}{l}\text { - overamplification } \\
\text { - triploidy }\end{array}$ & $3 n$ \\
\hline 7. & MET & $\begin{array}{l}4.3 \\
\text { (3-8/nucleus) }\end{array}$ & $\begin{array}{l}4.3 \\
\text { (3-8/nucleus) }\end{array}$ & 1 & $\begin{array}{l}\text { - no amplification } \\
\text { - tetraploidy }\end{array}$ & $4 n$ \\
\hline 8. & MET & $\begin{array}{l}3.1 \\
(2-4 / \text { nucleus })\end{array}$ & $\begin{array}{l}40.2 \\
\text { (15-60/nucleus) }\end{array}$ & 25.87 & $\begin{array}{l}\text { - overamplification } \\
\text { - triploidy }\end{array}$ & $3 n$ \\
\hline 9. & UNMET & $\begin{array}{l}3.0 \\
(2-5 / \text { nucleus })\end{array}$ & $\begin{array}{l}3.1 \\
(2-5 / \text { nucleus })\end{array}$ & 1.03 & $\begin{array}{l}\text { - no amplification } \\
\text { - triploidy }\end{array}$ & $3 n$ \\
\hline 10. & MET & $\begin{array}{l}2.1 \\
\text { (1-4/nucleus) }\end{array}$ & $\begin{array}{l}2.1 \\
\text { (1-4/nucleus) }\end{array}$ & 1 & - no amplification & $2 n$ \\
\hline 11. & MET & $\begin{array}{l}3.3 \\
(2-6 / \text { nucleus })\end{array}$ & $\begin{array}{l}25.9 \\
(22-40 / \text { nucleus })\end{array}$ & 7.55 & $\begin{array}{l}\text { - overamplification } \\
\text { - triploidy }\end{array}$ & $3 n$ \\
\hline 12. & UNMET & $\begin{array}{l}3.8 \\
(2-8 / \text { nucleus })\end{array}$ & $\begin{array}{l}3.8 \\
(2-8 / \text { nucleus })\end{array}$ & 1 & $\begin{array}{l}\text { - no amplification } \\
\text { - tetraploidy }\end{array}$ & $4 n$ \\
\hline 13. & MET & $\begin{array}{l}2.8 \\
(2-3 / \text { nucleus })\end{array}$ & $\begin{array}{l}2.8 \\
(2-3 / \text { nucleus })\end{array}$ & 1 & $\begin{array}{l}\text { - no amplification } \\
\text { - triploidy }\end{array}$ & $3 n$ \\
\hline 14. & UNMET & $\begin{array}{l}2.6 \\
(2-4 / \text { nucleus })\end{array}$ & $\begin{array}{l}3.3 \\
\text { (2-8/nucleus) }\end{array}$ & 1.27 & $\begin{array}{l}\text { - no amplification in } \\
\text { most of the nuclei } \\
\text { - triploidy }\end{array}$ & $3 n$ \\
\hline 15. & UNMET & $\begin{array}{l}3.9 \\
(2-8 / \text { nucleus })\end{array}$ & $\begin{array}{l}3.9 \\
(2-8 / \text { nucleus })\end{array}$ & 1 & $\begin{array}{l}\text { - no amplification } \\
\text { - tetraploidy }\end{array}$ & $4 n$ \\
\hline 16. & UNMET & $\begin{array}{l}2.1 \\
(2-3 / \text { nucleus })\end{array}$ & $\begin{array}{l}2.1 \\
(2-3 / \text { nucleus })\end{array}$ & 1 & - no amplification & $2 n$ \\
\hline 17. & UNMET & $\begin{array}{l}4.8 \\
(2-6 / \text { nucleus })\end{array}$ & $\begin{array}{l}5.1 \\
(2-6 / \text { nucleus })\end{array}$ & 1.1 & $\begin{array}{l}\text { - no amplification in } \\
\text { most of the nuclei } \\
\text { - pentaploidy }\end{array}$ & $5 n$ \\
\hline 18. & MET & $\begin{array}{l}2 \\
2 / \text { nucleus }\end{array}$ & $\begin{array}{l}2 \\
2 / \text { nucleus }\end{array}$ & 1 & - no amplification & $2 n$ \\
\hline 19. & MET & $\begin{array}{l}2.4 \\
\text { (1-6/nucleus) }\end{array}$ & $\begin{array}{l}2.4 \\
(1-6 / \text { nucleus })\end{array}$ & 1 & - no amplification & $2 n$ \\
\hline 20. & UNMET & $\begin{array}{l}2.1 \\
\text { (1-4/nucleus) }\end{array}$ & $\begin{array}{l}24.6 \\
(10-40 / \text { nucleus })\end{array}$ & 11.74 & - overamplification & $2 n$ \\
\hline 21. & MET & $\begin{array}{l}2.7 \\
(2-3 / \text { nucleus })\end{array}$ & $\begin{array}{l}40 \\
\text { (12-60/nucleus) }\end{array}$ & 14.8 & $\begin{array}{l}\text { - overamplification } \\
\text { - triploidy }\end{array}$ & $3 n$ \\
\hline
\end{tabular}




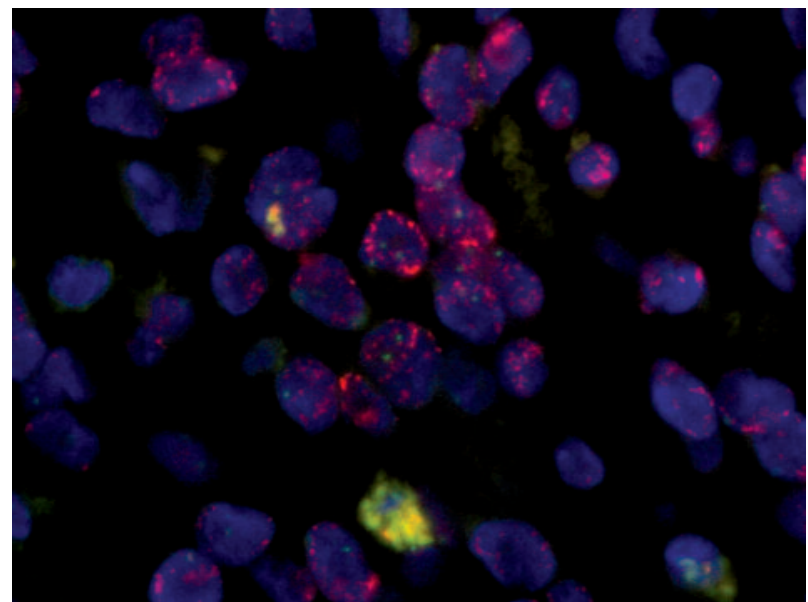

Fig. 1. MGMT promoter methylation and EGFR amplification present (enhanced orange signal due to EGFR gene multiplication)

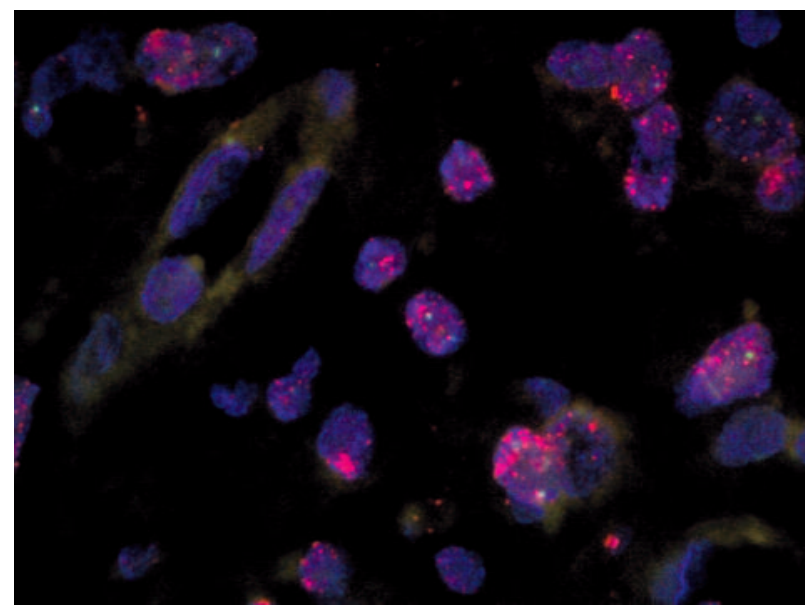

Fig. 3. No MGMT promoter methylation, EGFR amplification present (orange signal for EGFR gene multiplication)

cant difference in progression-free survival among the MGMT promoter methylation group - those treated with radiochemotherapy (temozolomide) have had progression-free survival of 10.3 months vs. 5.9 months (radiotherapy alone). It suggests that the MGMT promoter methylation is a positive predictive factor in temozolomide therapy for glioblastoma in newly diagnosed patients. Since then, radiotherapy alone has no longer been an accepted standard of treatment in newly diagnosed glioblastoma. MGMT promoter methylation study showed promising results in the CENTRIC trial also. This project has investigated cilengitide - a first-in-class integrin targeting polypeptide. It was found that MGMT methylated glioblastoma patients (30-35\%) responded with a gain in the progression-free survival from the combined radiochemotherapy (temozolomide plus cilengitide) [5].

The molecular findings are expected to be useful in clinical conditions to facilitate decisions as for the treatment of choice. MGMT promoter methylation is already an advocated factor in the treatment decisions in glioblastoma patients. Based on the MGMT status the homogeneous groups of patients most likely to benefit from the particular treatment (alkylating agents) are defined. Unfortunately, available

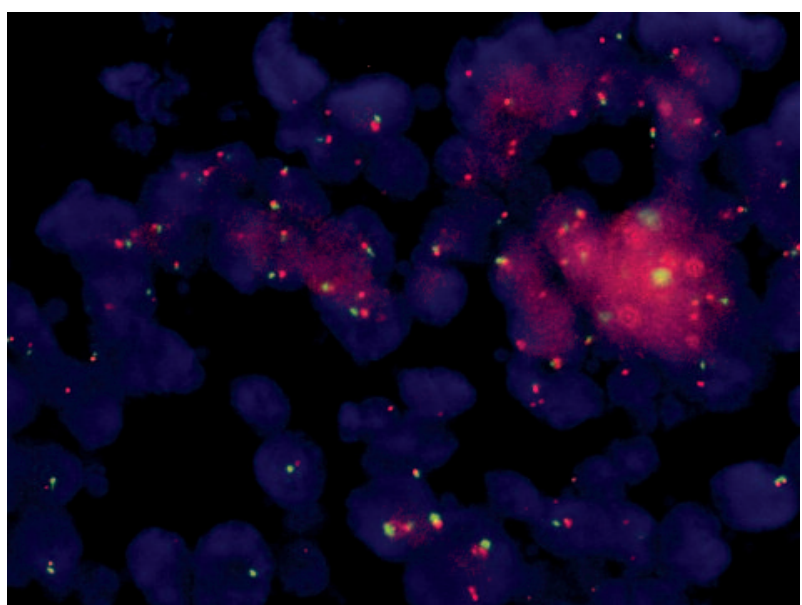

Fig. 2. MGMT promoter methylation present, no EGFR amplification (characteristic pairs of orange and green signal for both investigating and control molecular probe of EGFR gene detection - normal number of EGFR copies)

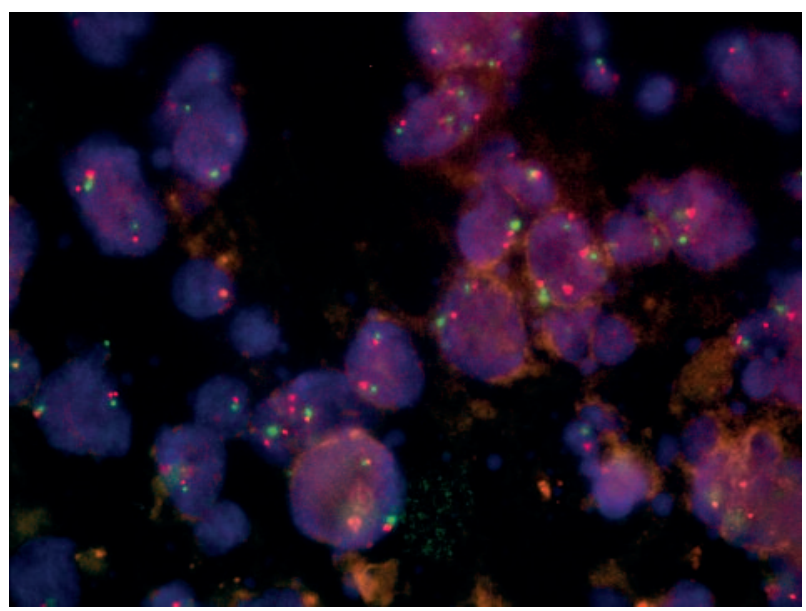

Fig. 4. No MGMT promoter methylation, no EGFR amplification (as in Fig. 2, orange and green signals form pairs)

data do not support any particular treatment in relation to the molecular features of the tumour. The implementation of MGMT status evaluation into the glioblastoma treatment process requires standardization of the MGMT methylation assessment techniques; for now it is deemed that only methylation-specific PCR can provide repeatable, clinically useful information, whereas all other methods are of experimental value. Moreover, even MS-PCR has not met criteria of reproducibility across the laboratories and the necessity of validation of protocols has been stressed [6]. As a result, MGMT methylation status evaluated in this way cannot be regarded as the conditioning factor for temozolomide (the only proven active agent against glioblastoma) [2].

The current routine histopathological diagnosis of high grade gliomas does not enable ideal correlation with the outcome; therefore it is expected that the molecular features may help to expand or substantially contribute to glioma classification. It is well known that the anaplastic glioma studies need $1 \mathrm{p} / 19 \mathrm{q}$ codeletion and MGMT promoter methylation stratification (CATNON, CODEL) and the newly diagnosed glioblastoma trials need MGMT promoter status evaluation (CENTRIC); both molecular markers carry 
a strong prognostic value, which independently influences the patients' outcome [2]. Especially the associations between different molecular biomarkers require further investigations (e.g. 1p/19q codeletion and IDH1 mutations are extremely rare in glioblastomas and might even be considered as incompatible with the diagnosis of glioblastoma in the future) $[7,8]$. A very basic and still important question is the range of MGMT promoter methylation in the glioblastoma. In our series of unselected and consecutive cases of GBM, 10/21 (47.6\%) showed MGMT promoter hypermethylation. This result is similar to other reports [9].

\section{EGFR amplification}

Epidermal growth factor receptor (EGFR) amplification in glioblastoma has been widely investigated [10-16]. EGFR amplification and overexpression is a part of the molecular pathway leading to secondary glioblastoma development. EGFR overexpression has been found in $40-50 \%$ of glioblastoma cases and is a sign of late tumour progression linked to clinical malignancy. For this reason, EGFR amplification is considered an unfavourable prognostic factor in glioblastoma. In about $50 \%$ of tumours with EGFR amplification variant III of EGFR is amplified, which carries worse prognosis in terms of a poorer survival rate and shorter interval to clinical relapse [10]. Increased EGFR amplification seems to be related to increased tumour cell proliferation and immortality (resistance to apoptosis), migration, angiogenesis and infiltration. All of those result from the pathological continuous EGF receptor activity and consequently activation of the PI3-K/Akt pathway and MAPK/extracellular signal-regulated kinases 1/2 (ERK1/2) pathway [11]. EGFR signalling inhibition looks promising as a treatment option in glioblastoma. It is possible in different ways: by monoclonal antibodies blocking the ligand site in the tumour cell membrane that leads to receptor internalisation, by ligand-toxin/radioimmuno agents, by intracellular tyrosine kinase inhibitors (EGFR-TKI), or else by decrease of EGFR expression (antisense oligonucleotides, ribozymes and small interfering RNA) [10-15]. The clinical trials of EGFR-TKI erlotinib and gefitinib are ongoing. The first results are controversial [8, 13-16]. While in one study the satisfactory result of treatment was strongly associated with EGFR overexpression [11], in another this correlation could not be confirmed [13]. Recently Peereboom et al. reported negative results of bimodal adjuvant treatment of GBM with temozolomide and the EGFR inhibitor erlotinib [16], though it seems that the question has not been definitely solved and the proper selection of patients for treatment remains a crucial factor.

To sum up, the known glioblastoma molecular status gives the possibility to define a homogeneous group of patients most likely to benefit from the particular way of treatment. The investigation of the co-occurrence of MGMT methylation status and amplification of EGFR could result in the recruitment of patients potentially sensitive to both temozolomide and antiEGFR agents and thus in the definition of a more "pharmacologically homogeneous' group. Our results suggest that both MGMT methylation and EGFR amplification segregate independently. These results do not differ significantly from those of Prerana et al., who found EGFR amplification in 30.4\% of GBMs with MGMT hypermethylation (in our material - 40\%), and in $42.1 \%$ of cases without MGMT hypermethylation (in our material -36.4\%) [7]. In our study in about $19 \%$ of cases it was possible to show both molecular biomarkers and therefore supposedly we may estimate that approximately at least $1 / 5 \mathrm{GBM}$ patients could benefit from the combined treatment with temozolomide and one of the agents acting via EGFR.

\section{Acknowledgements}

This work has been supported by Jagiellonian Univ. Grant No. K/ZDS/001044. The study has the acceptance of the Bioethical Committee at Jagiellonian University.

\section{References}

1. Loew S, Schmidt U, Unterberg A, Halatsch ME. The epidermal growth factor receptor as a therapeutic target in glioblastoma multiforme and other malignant neoplasms. Anticancer Agents Med Chem 2009; 9: 703-15.

2. Tabatabai G, Stupp R, van den Bent MJ, Hegi ME, Tonn JC, Wick W, Weller M. Molecular diagnostic of gliomas: the clinical perspective. Acta Neuropathol 2010; 120: 585-92.

3. www.ClinicalTrials.gov Identifier: NCT00626990.

4. www.ClinicalTrials.gov Identifier: NCT00887146.

5. www.ClinicalTrials.gov Identifier: NCT00689221.

6. Weller M, Stupp R, Reifenberger G, Brandess AA, van den Bent MJ, Wick W, Hegi ME. MGMT promoter methylation in gliomas: ready for personalized medicine? Nat Rev Neurol 2010; 6: 39-51.

7. Prerana J, Vaishali S, Ayushi J, et al. $0^{6}$-Methylguanine DNA methyltransferase gene promoter methylation status in gliomas and its correlation with other molecular alterations: first Indian report with review of challenges for use in customized treatment. Neurosurgery 2010; 67: 1681-91.

8. Brown PD, Krishnan S, Sarkaria JN, et al. Phase I/II trial of erlotinib and temozolomide with radiation therapy in the treatment of newly diagnosed glioblastoma multiforme: North Central Cancer Treatment Group Study N0177. I Clin Oncol 2008; 26: 5603-9.

9. Dunn J, Baborie A, Alam F, et al. Extent of MGMT promoter methylation correlates with outcome in glioblastomas given temozolomide and radiotherapy. Br J Cancer 2009; 101: 124-31.

10. Hatanpaa KJ, Burma S, Zhao D, Habib AA. Epidermal growth factor receptor in glioma: signal transduction, neuropathology, imaging, and radioresistance. Neoplasia 2010; 12: 675-84.

11. Haas-Kogan DA, Prados MD, Tihan T, et al. Epidermal growth factor receptor, protein kinase $\mathrm{B} / \mathrm{akt}$, and glioma response to erlotinib. J Natl Cancer Inst 2005; 97: 880-7.

12. Mellinghoff IK, Wang MY, Vivanco I, et al. Molecular determinants of the response of glioblastomas to EGFR kinase inhibitors. N Engl J Med 2005; 353: 2012-24.

13. Rich JN, Reardon DA, Perry T, et al. Phase II trial of gefitinib in recurrent glioblastoma. J Clin Oncol 2004; 22: 133-42.

14. Prados MD, Lamborn KR, Chang S, et al. Phase 1 study of erlotinib $\mathrm{HCl}$ alone and combined with temozolomide in patients with stable or recurrent malignant glioma. Neuro Oncol 2006; 8: 67-78.

15. Yung WK, Vredenburgh JJ, Cloughesy TF, Nghiemphu P, Klencke B, Gilbert MR, Reardon DA, Prados MD. Safety and efficacy of erlotinib in first-relapse glioblastoma: a phase II open-label study. Neurooncology 2010; 12: 1061-70.

16. Peereboom DM, Shepard DR, Ahluwalia MS, et al. Phase II trial of erlotinib with temozolomide and radiation in patients with newly diagnosed glioblastoma multiforme. J Neurooncol. 2010; 98: 93-9.

\section{Address for correspondence}

\section{Dariusz Adamek}

Department of Neurosurgery

Jagiellonian University Medical College

Grzegórzecka 16

31-531 Kraków

e-mail: mnadamek@cyf-kr.edu.pl 